\title{
Green Synthesis of Zinc Oxide Nanoparticles Using Ixora Coccinea Leaf Extract for Ethanol Vapour Sensing
}

\author{
Leela Pradhan Joshi, Bal Vikram Khatri, Sumana Gyawali, Shiromani Gajurel, \\ and Dinesh Kumar Chaudhary*
}

Department of Physics, Amrit Campus, Tribhuvan University, Kathmandu, 44600, Nepal

*Corresponding author: dinesh.chaudhary@ac.tu.edu.np

Published online: 25 August 2021

To cite this article: Joshi, L. P. et al. (2021). Green synthesis of zinc oxide nanoparticles using Ixora Coccinea leaf extract for ethanol vapour sensing. J. Phys. Sci., 32(2), 15-26. https://doi.org/10.21315/jps2021.32.2.2

To link to this article: https://doi.org/10.21315/jps2021.32.2.2

\begin{abstract}
This article reports the effects of natural plant proteins on the morphology of zinc oxide nanoparticles (ZnONPs) prepared via a precipitation method. Green synthesised ZnONPs have a wide range of uses such as biomedical applications, water purification, optical devices and gas sensors. The non-toxic and economical technique described in this article is favourable for large-scale production too. ZnONPs were produced from a zinc acetate precursor with dye extract of Ixora Coccinea (IC) leaves as a capping agent. The as-prepared ZnONPs were characterised by X-ray diffraction (XRD), Fourier transform infrared (FTIR), UV-visible ( $U V$-vis), scanning electron microscopy (SEM) and energy dispersive X-ray (EDX) techniques. The XRD analysis showed an average crystallite size of $23 \mathrm{~nm}$. The SEM analysis revealed a reduction in aggregation of $\mathrm{ZnO}$ crystallites due to addition of dye extracts of IC. EDX and UV-vis results confirmed the formation of pure ZnONPs. Finally, the gas sensing properties of $\mathrm{ZnO}$ films, prepared by doctor blade method, were used to detect ethanol vapour. The results showed gas response ratios of 28.7 and 5.4 at 800 ppm and 40 ppm exposure, respectively. Furthermore, the response time and recovery time were found to be $24 \mathrm{sec}$ and $47 \mathrm{sec}$, respectively at 200 ppm exposure of ethanol vapour.
\end{abstract}

Keywords: green synthesis, metal oxide semiconductor, nanoparticles, Ixora Coccinea, gas response 


\section{INTRODUCTION}

Nanomaterials are classified based on their size. Their size ranges from one to a few hundred nanometers. Materials at this scale show enhanced physical and chemical properties as compared to their bulk size. Nanoparticles of metal and metal oxide semiconductors (MOS) such as silver, iron oxide, tin oxide and zinc oxide are currently being used in several technologies such as photocatalytic dye degradation, biomedical and optoelectronic devices and gas sensing. ${ }^{1-5}$ Among various MOS nanoparticles, zinc oxide nanoparticles (ZnONPs) have garnered significant attention for their use in applications such as gas sensors, biosensors, pollution control and piezoelectric devices. This is primarily because of their high mobility and reactivity, biocompatibility and high chemical and thermal stability. ${ }^{6-7}$ As such ZnONPs present an opportunity to further develop material science.

$\mathrm{ZnO}$ possesses fascinating properties such as a large band gap $(3.37 \mathrm{eV})$ and exciton binding energy $(60 \mathrm{meV})$, high transparency and easy tuning of electrical and optical behaviour. $\mathrm{ZnO}$ can be prepared to different morphologies such as nanoflowers, nanoparticles, nanosheets, nanorods, nanowires and hexagonal prismatic crystals using various conventional and new green synthesis methods. ${ }^{8-11}$ Many of the available conventional physical and chemical processes used to synthesis metal oxide semiconductor nanoparticles (MOSNPs) are expensive and energy intensive. ${ }^{9}$ They also produce substantial quantities of toxic byproducts, prompting concerns for waste storage and removal. On the other hand, the green synthesis method, wherein plant extracts are used to prepare metal and metal oxide nanoparticles, is a cost-effective and alternative route with a reduced toxic waste load. ${ }^{12-20}$ Currently, ZnONPs have been synthesised using the extracts of Aloe barbadensis miller, Black tea, Citrus aurantifolia, Peltophorumpterocarpum, Cyanometraramiflora and surfactants such as sodium dodecyl sulfate (SDS), cetyltrimethylammonium bromide (CTAB) ${ }^{21-26}$ However, there has been limited work done on the synthesis of ZnONPs using dye extracts of the leaves from Ixora Coccinea (IC). ${ }^{27}$

Since the sensing performance of $\mathrm{ZnO}$ sensor depends on the interactions of gas molecules with the adsorbed oxygen ions $\left(\mathrm{O}_{2}{ }^{-}\right.$or $\left.\mathrm{O}^{-} / \mathrm{O}^{2-}\right)$ on its surface, the surface morphology of $\mathrm{ZnO}$ plays an important role. The surface structure of $\mathrm{ZnO}$ can be modified by strategies like metal doping and surface treatment. ${ }^{28-29} \mathrm{Among}$ them, the addition of proteins and other phytochemicals from the natural plant is considered a significant one as it enhances the stability of the nanoparticles. ${ }^{19}$ In this process, the extract's presence not only aids in controlling the growth parameters such as aggregation of crystallites but also forms pure and narrow 
particle size distributed materials.${ }^{27}$ The present study describes the preparation of ZnONPs using dye extracts of IC leaves, its characterisation and its utilisation in the detection of ethanol vapour.

\section{EXPERIMENTAL}

\subsection{Materials}

IC leaves were collected from Calicut, Kerala, India. The most significant compounds in this plant extract are its hydroxyl and carbonyl groups. The phenolics and alkaloids present in the extract are responsible for capping the $\mathrm{ZnO}$ nanoparticles. ${ }^{27}$ Zinc acetate dehydrate was used as a metal ion precursor and sodium hydroxide $(\mathrm{NaOH})$ as a precipitating agent.

\subsection{Preparation of the Dye Extract}

First, fresh leaves of the IC plant were washed several times with distilled water. Then, they were dried and grinded at room temperature. Ten grams of grinded leaves were mixed with $40 \mathrm{ml}$ of distilled water and heated to $60^{\circ} \mathrm{C}$ for $30 \mathrm{~min}$, followed by filtration to remove the solid extract. Finally, the fine solution of dye extract of IC was preserved in a vessel for further study.

\subsection{Preparation of $\mathrm{ZnONPs}$ and Film}

An aqueous solution of $0.5 \mathrm{M}$ zinc acetate dehydrate was mixed with $10 \mathrm{ml}$ of above-prepared dye extract. The $2.0 \mathrm{M} \mathrm{NaOH}$ was added drop wise to this solution while stirring continuously for $2 \mathrm{~h}$. The $\mathrm{pH}$ of the mixture solution was maintained at 12 . The precipitate was then washed and left for a day for sedimentation to occur. Afterward, it was separated from the upper supernatant liquid by a simple decantation process followed by centrifuging vigorously four times at 1,500 rpm for $10 \mathrm{~min}$ each. Finally, the yield was dried at $100^{\circ} \mathrm{C}$ in a dry air oven for $16 \mathrm{~h}$. A sample of ZnONPs without the dye extract was also prepared following the same procedure for comparison. Both sets, ZnONPs with IC and ZnONPs without IC, were then deposited on a transparent conducting fluorine-doped tin oxide (FTO) substrate using the conventional doctor blade method. The deposited $\mathrm{ZnO}$ films were annealed at $550^{\circ} \mathrm{C}$ inside the muffle furnace. Finally, the film's sensing performances were tested with various concentrations of ethanol vapour. 


\section{RESULTS AND DISCUSSION}

\subsection{X-ray Diffraction (XRD)}

The structural properties of ZnONPs prepared by the precipitation method were studied using XRD with Bruker D2 Phaser (Germany) Diffractometer of Cu$\mathrm{K}_{\alpha}$ radiation of wavelength $1.54184 \AA$ at $30 \mathrm{kV}$ operating voltage and $10 \mathrm{~mA}$ current in the $2 \theta$ range of $20^{\circ}$ to $80^{\circ}$ at a scanning rate of 0.33 degree per second at Charotar University of Science \& Technology, CHARUSAT-Campus, India. The crystallite size (D) was calculated using Debye Scherrer's formula: $D=\frac{0.9 \lambda}{\beta \cos \theta}$ where 0.9 is the correction factor, $\lambda$ is the wavelength of the $\mathrm{X}$-radiation, $\beta$ is the full width half maximum (FWHM) measured in radian of the diffraction peak and $\theta$ is the Bragg's angle. ${ }^{14}$ The XRD powder patterns of ZnONPs prepared with and without IC are shown in Figure 1. The figure illustrated multiple peaks oriented along (100), (002), (101), (102), (110), (103), (200), (112), (201), (004) and (202). All the peaks are indexed concerning the standard JCPDS values of card number 36-1451. ${ }^{24}$ The multiple sharp peaks observed in the XRD patterns are characteristics of the polycrystalline nature of $\mathrm{ZnO}$. The calculated values of average crystallite size (D) and lattice parameters of both sets of ZnONPs are shown in Table 1. The result showed the average value of $D$ was $23.80 \mathrm{~nm}$ for $\mathrm{ZnONPs}$ prepared with IC and $22.02 \mathrm{~nm}$ for $\mathrm{ZnONPs}$ without IC. The c/a ratio

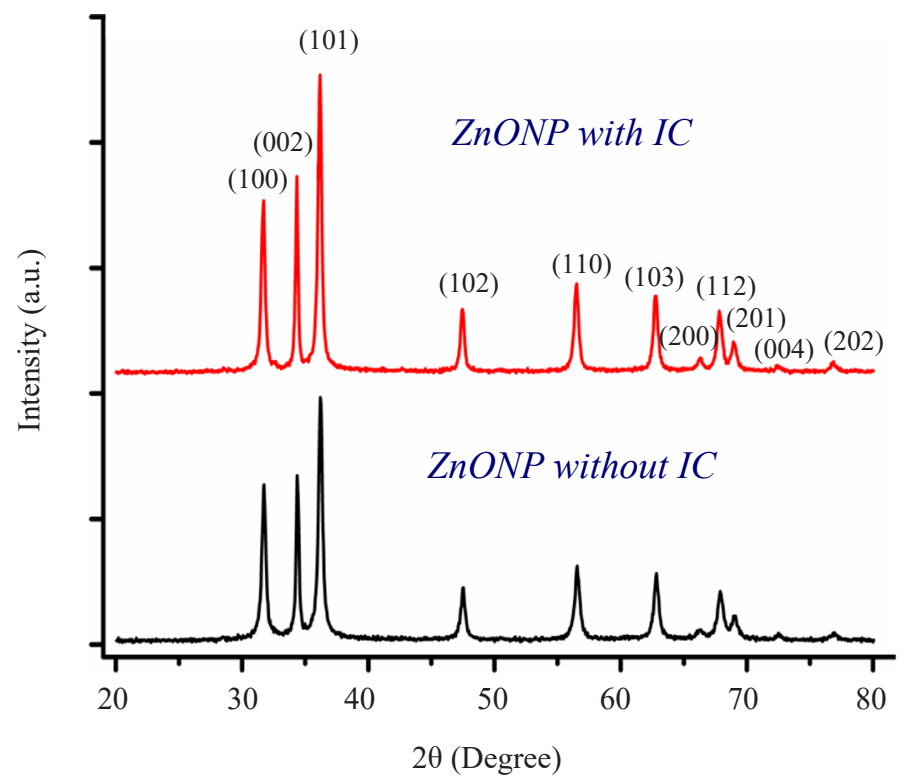

Figure 1: XRD patterns of as-prepared ZnONPs. 
for both samples was 1.6 suggesting the wurtzite hexagonal phase of $\mathrm{ZnO}$. There was no observation of other impurity peaks in the XRD pattern, proving that the as-prepared $\mathrm{ZnONPs}$ are of high purity.

Table 1: Calculated average crystallite size and lattice parameters of ZnONPs.

\begin{tabular}{lccc}
\hline \multirow{2}{*}{ Samples } & Average crystallite size $(\mathrm{nm})$ & \multicolumn{2}{c}{ Lattice parameters $(\AA)$} \\
\cline { 3 - 4 } & & $\mathrm{a}$ & $\mathrm{c}$ \\
\hline ZnONP with IC & 23.08 & 3.01547 & 5.2229 \\
ZnONP without IC & 22.02 & 3.25662 & 5.2150 \\
\hline
\end{tabular}

\subsection{Scanning Electron Microscopy (SEM)}

Figure 2(a) and 2(b) illustrates the SEM images of ZnONPs prepared without and with dye extract at a resolution of $200 \mathrm{~nm}$. The captured images revealed the aggregated clusters of $\mathrm{ZnO}$ crystallites.$^{24}$ Figure 2(b) clearly shows the less aggregated morphology of ZnONPs which was due to the presence of IC extract acting as a capping agent.
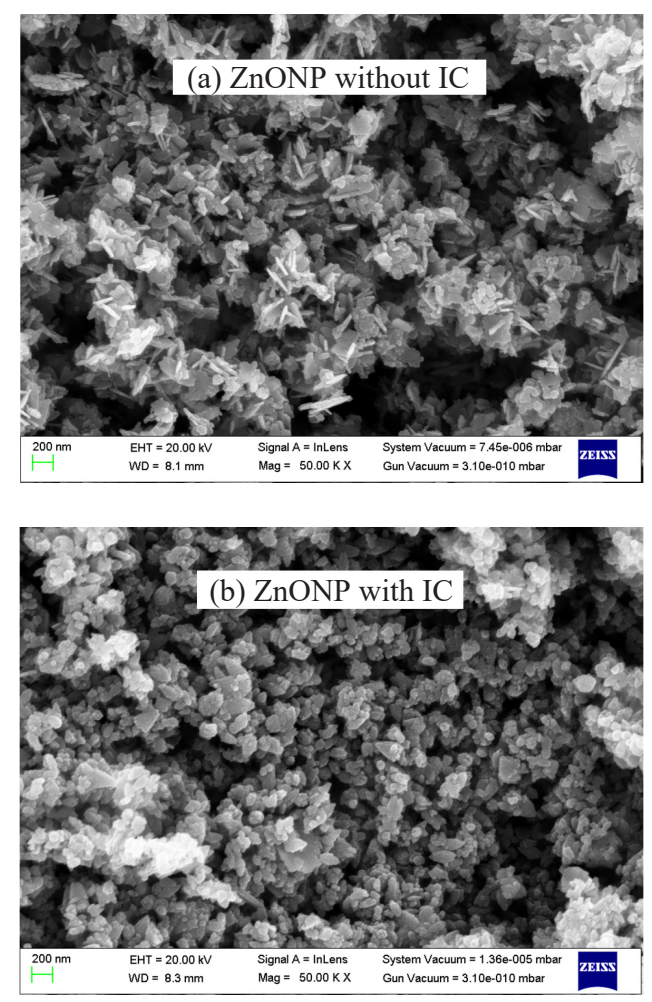

Figure 2: SEM images ZnONPs (a) without IC and (b) with IC. 


\subsection{Energy Dispersive X-ray (EDX) Analysis}

The results of the EDX performed to uncover the elemental composition of the synthesised ZnONPs with and without dye extract, are portrayed in Figure 3. The figure clearly shows two sharp peaks at $1.0 \mathrm{keV}$ and $8.5 \mathrm{keV}$ and a lower one at $0.5 \mathrm{keV}$, the characteristic features of zinc and oxygen. These results agreed with the reported values. ${ }^{13}$ The atomic percentage of the present elements were $55.43 \%$ of zinc and $44.57 \%$ of oxygen in bare ZnONPs (Figure 3[a]) and $53.80 \%$ of zinc and $46.20 \%$ of oxygen for ZnONPs prepared with IC (Figure 3[b]). The results confirmed the high purity of as-synthesised ZnONPs.
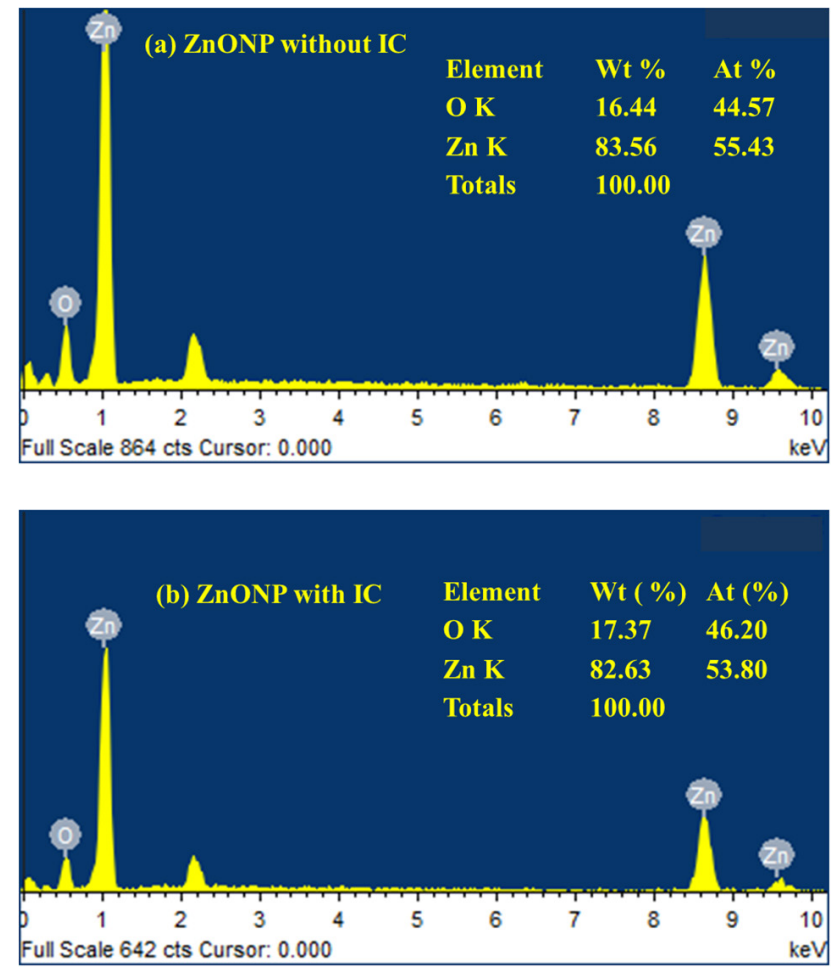

Figure 3: EDX spectra of ZnONPs (a) without IC and (b) with IC.

\subsection{Fourier Transforms Infrared (FTIR) and UV-Visible (UV-vis) Spectroscopy}

Figure 4(a) depicts the FTIR spectrum of ZnONPs synthesised with IC in the wavenumber range of $400 \mathrm{~cm}^{-1}$ to $4,000 \mathrm{~cm}^{-1}$. It clearly shows major bands at $400 \mathrm{~cm}^{-1}, 574 \mathrm{~cm}^{-1}, 880 \mathrm{~cm}^{-1}, 1,407 \mathrm{~cm}^{-1}, 1,628 \mathrm{~cm}^{-1}$ and $3,420 \mathrm{~cm}^{-1}$. The sharp infrared (IR) band extends from $400 \mathrm{~cm}^{-1}$ 
to $650 \mathrm{~cm}^{-1}$ corresponding to metal oxide vibration confirmed the formation of ZnONPs. The peak at $880 \mathrm{~cm}^{-1}$ indicated the alkane $\mathrm{sp}^{2}$ hybridised $=\mathrm{C}-\mathrm{H}$ bond and the alkane $\mathrm{sp}^{3}$ hybridised $\mathrm{C}-\mathrm{H}$ bond bending, respectively. ${ }^{12}$ The peaks in the regions $1,407 \mathrm{~cm}^{-1}$ and $1,628 \mathrm{~cm}^{-1}$ were ascribed to the vibrating, stretching, and bending modes of water molecules present in the sample respectively. Finally, a huge depression peak at $3,420 \mathrm{~cm}^{-1}$ showed the presence of hydroxyl group. ${ }^{13}$ The UV-vis absorption spectrum was captured using an Ocean Optics spectrophotometer (Model: HR4000CG-UV-NIR, Singapore), to confirm the formation of ZnONPs as depicted in Figure 4(b). The peak observed at $340 \mathrm{~nm}$ as certained the formation of ZnONPs.

(a)

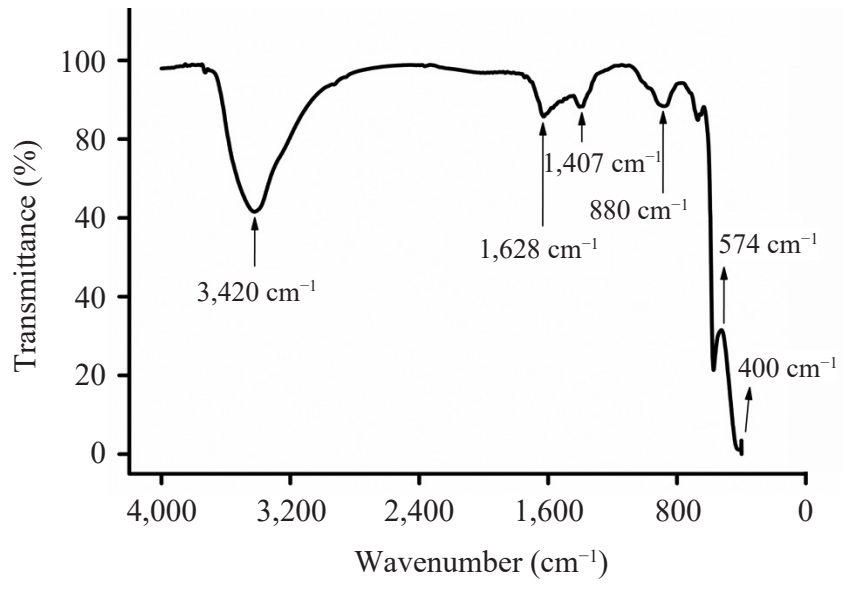

(b)

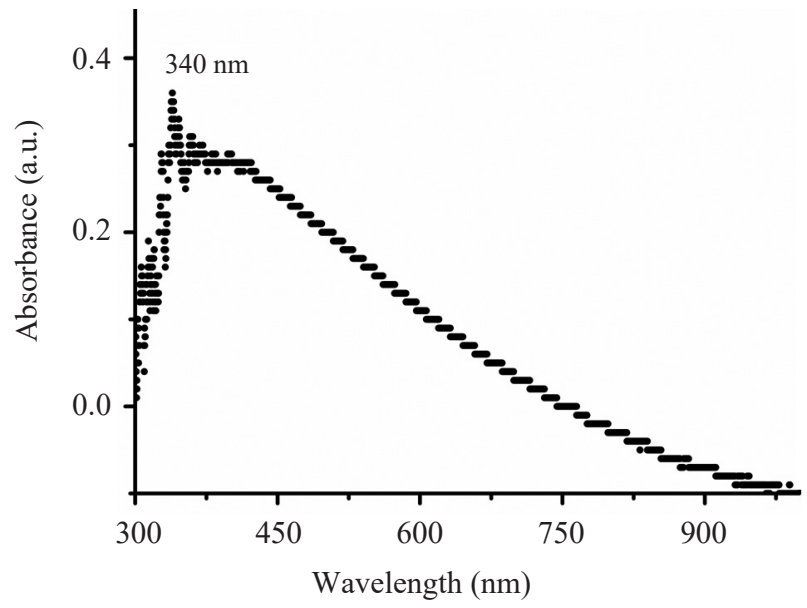

Figure 4: (a) FTIR and (b) absorbance of ZnONPs prepared with dye extract of IC. 


\subsection{Sensitivity Measurements}

The gas response was calculated by measuring the ratio of $R_{a} / R_{g}$, where $R_{a}$ and $\mathrm{R}_{\mathrm{g}}$ are the resistances of $\mathrm{ZnO}$ measured in air and gas, respectively. The electrical resistance of MOS is a temperature-sensitive property so its working temperature must be optimised..$^{29}$ Figure 5(a) shows the optimised temperature of $285^{\circ} \mathrm{C}$ for both samples. Figure 5(b) illustrated the linear increment of gas response with increasing gas concentration measured at its optimised temperature. The measured values of gas response, response and recovery times were shown in Table 2. It shows a gas response of 28.7 for $\mathrm{ZnO}$ with IC and 37.4 for $\mathrm{ZnO}$ without IC at $800 \mathrm{ppm}$ of ethanol exposure. The difference in these values may be due to the change in the morphology of $\mathrm{ZnO}$. The gas response ratios were 5.4 and 3.5 for $40 \mathrm{ppm}$ exposure of ethanol vapour. The inset in Figure 5(b) shows the response and recovery times of $\mathrm{ZnO}$ sensors with $200 \mathrm{ppm}$ exposure of ethanol vapour for clarity. The response and recovery times were respectively $24 \mathrm{sec}$ and $47 \mathrm{sec}$ for $\mathrm{ZnO}$ with IC, whereas these values were respectively $21 \mathrm{sec}$ and $27 \mathrm{sec}$ for $\mathrm{ZnO}$ without IC.

Table 2: Gas response, response and recovery times of the $\mathrm{ZnO}$ sensors.

\begin{tabular}{ccccccccc}
\hline \multirow{2}{*}{$\begin{array}{c}\text { Concentration } \\
\text { of ethanol }(\mathrm{ppm})\end{array}$} & \multicolumn{3}{c}{ ZnO without IC } & & \multicolumn{3}{c}{ ZnO with IC } \\
\cline { 2 - 4 } \cline { 6 - 8 } & $\begin{array}{c}\text { Response } \\
\mathrm{R}_{\mathrm{a}} / \mathrm{R}_{\mathrm{g}}\end{array}$ & $\begin{array}{c}\text { Response } \\
\text { time }(\mathrm{sec})\end{array}$ & $\begin{array}{c}\text { Recovery } \\
\text { time }(\mathrm{sec})\end{array}$ & & $\begin{array}{c}\text { Response } \\
\mathrm{R}_{\mathrm{a}} / \mathrm{R}_{\mathrm{g}}\end{array}$ & $\begin{array}{c}\text { Response } \\
\text { time (sec) }\end{array}$ & $\begin{array}{c}\text { Recovery } \\
\text { time }(\mathrm{sec})\end{array}$ \\
\hline 40 & 3.50 & 15 & 33 & & 5.47 & 23 & 50 \\
80 & 3.97 & 21 & 27 & & 5.56 & 26 & 51 \\
120 & 4.38 & 23 & 23 & & 6.22 & 25 & 49 \\
160 & 6.20 & 23 & 25 & & 9.94 & 27 & 46 \\
200 & 19.28 & 21 & 27 & & 10.23 & 24 & 47 \\
400 & 26.16 & 24 & 27 & & 13.63 & 27 & 49 \\
800 & 37.43 & 19 & 25 & & 28.76 & 26 & 49 \\
\hline
\end{tabular}


(a)

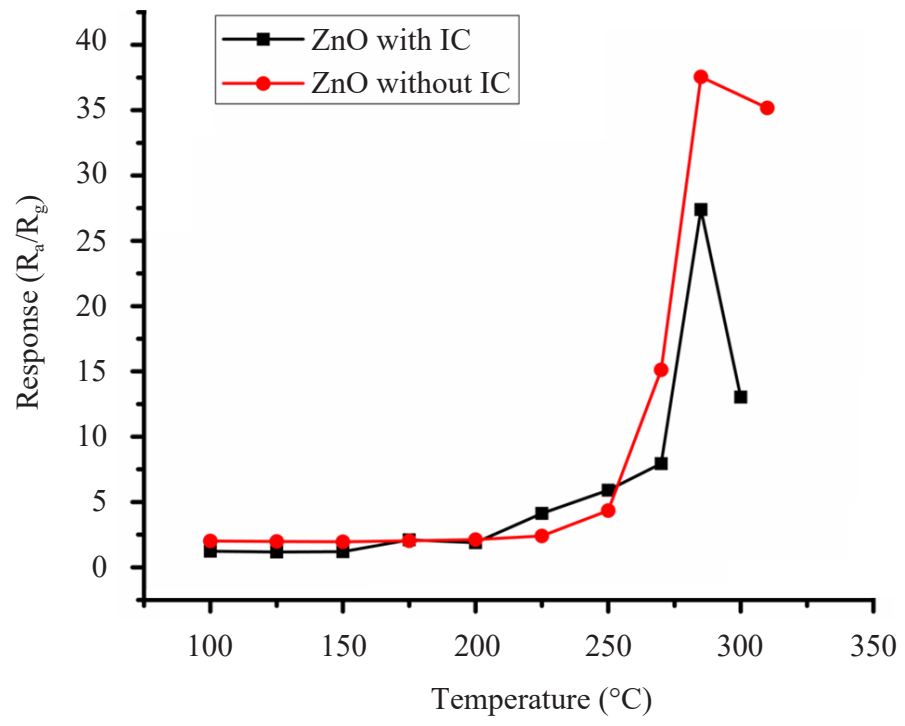

(b)

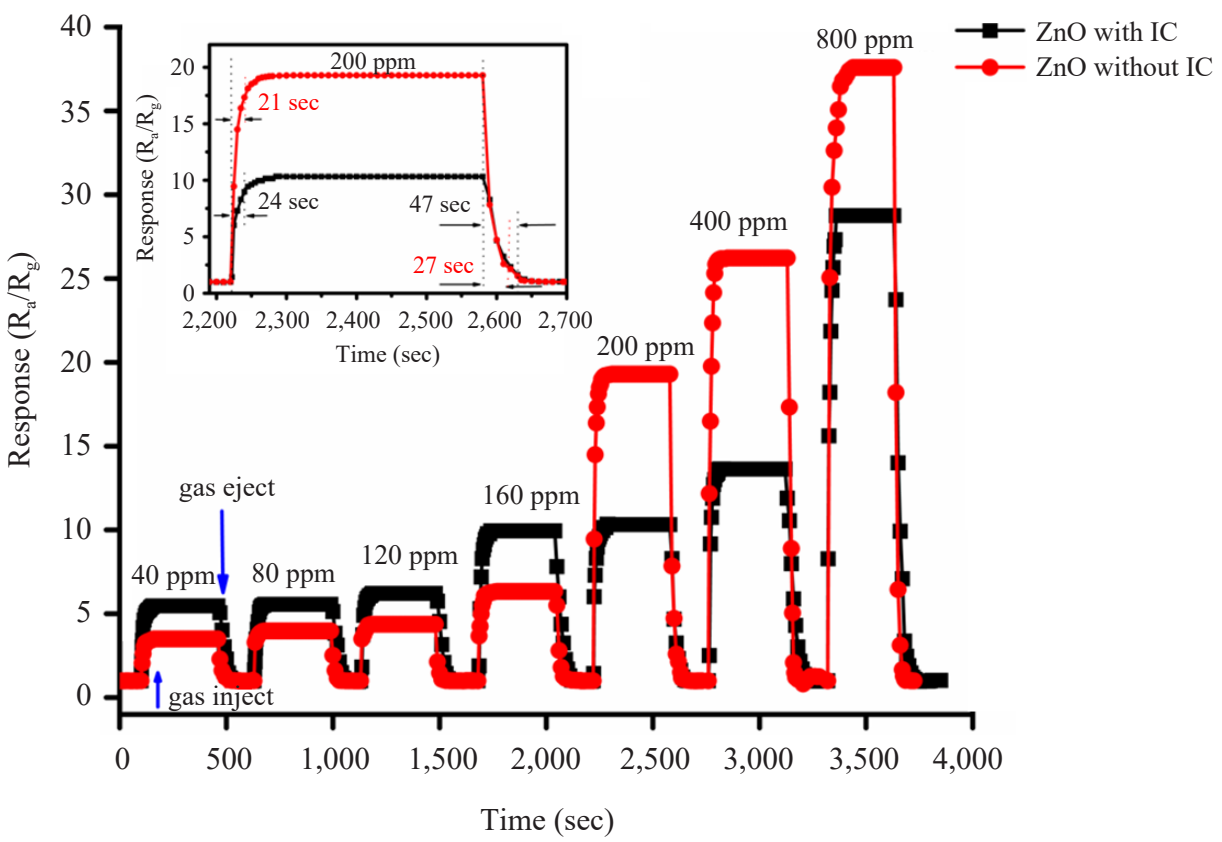

Figure 5: Response characteristics of $\mathrm{ZnO}$ film as a function of (a) temperature and (b) gas concentration. 


\section{CONCLUSION}

ZnONPs were successfully fabricated using dye extract of IC leaves as a capping agent by precipitation method. Investigations of morphology, structure and dimension of ZnONPs were performed by SEM, XRD and UV-vis analyses. The average crystallite size of ZnONPs was found to be $23 \mathrm{~nm}$. The SEM investigation illustrated the change in morphology of $\mathrm{ZnO}$ from highly clustered to less aggregate clustered of $\mathrm{ZnO}$ crystallites after IC dye extract was added. Furthermore, the presence of hydroxyl groups, $\mathrm{ZnO}$ bands and the percentage content of zinc and oxygen were established by FTIR and EDX, respectively. The sensitivity results of $\mathrm{ZnO}$ film prepared with IC showed a gas response ratio of 28.7 and 5.4 for the exposure of $800 \mathrm{ppm}$ and $40 \mathrm{ppm}$ of ethanol vapour, respectively.

\section{ACKNOWLEDGEMENTS}

The authors would like to thank the University Grants Commission (UGC), Nepal for providing financial support under FRG-73-74-S \& T-09 to complete this research work. The authors would also like to thank Charotar University of Science and Technology CHARUSAT-Campus and the Indian Institute of Technology (IIT), India for the support in conducting FTIR, XRD, SEM and EDX experiments.

\section{REFERENCES}

1. Vinayagam, R. et al. (2020). Structural characterization of green synthesized $\alpha-\mathrm{Fe}_{2} \mathrm{O}_{3}$ nanoparticles using the leaf extracts of Spodias dulcis. Surf. Interface, 20, 100618. https://doi.org/10.1016/j.surfin.2020.100618

2. Varadavenkatesan, T., Selvaraj, R. \& Vinayagam, R. (2020). Green synthesis of silver nanoparticles using Thunbergia gradiflora flower extract and its catalytic action in reduction of Congo red dye. Mater. Today: Proceeds., 23(1), 39-42. https://doi.org/10.1016/j.matpr.2019.05.441

3. Bhatia, S., Verma, N. \& Bedi, R. K. (2017). Ethanol gas sensor based upon $\mathrm{ZnO}$ nanoparticles prepared by different techniques. Results in Phys., 7, 801-806. https://doi.org/10.1016/j.rinp.2017.02.008

4. Inderan, V. et al. (2019). A comparative study of structural and ethanol gas sensing properties of pure, nickel and palladium doped $\mathrm{SnO}_{2}$ nanorods synthesized by the hydrothermal method. J. Phys. Sci., 30(1), 127-143. https://doi.org/10.21315/ jps2019.30.1.10

5. Hamady, S. O. S. et al. (2019). Development of novel thin film solar cells: Design and numerical optimization. J. Phys. Sci., 30 (Supp.2), 199-205. https://doi.org/ 10.21315/jps2019.30.s2.17 
6. Fardood, S. T. et al. (2020). Facile green synthesis and characterization of zinc oxide nanoparticles using tragacanthgel: Investigation of their photocatalytic performance for dye degradation under visible light irradiation. Nanochem. Res., 5(1), 69-76. https://doi.org/10.22036/ncr.2020.01.007

7. Wang, X. et al. (2006). Piezoelectric field effect transistor and nanoforce sensor based on a single $\mathrm{ZnO}$ nanowire. Nano Lett. 6(12), 2768-2772. https://doi.org/ $10.1021 / \mathrm{nl} 061802 \mathrm{~g}$

8. Vinayagam, R. et al. (2020). Synthesis, characterization and photocatalytic dye degradation capability of Calliandra haematocephala mediated zinc oxide nanoflowers. J. Photochem. and Photobiol. B: Biol., 203, 111760. https://doi.org/ 10.1016/j.jphotobiol.2019.111760

9. Liu, X. et al. (2004). Growth mechanism and properties of $\mathrm{ZnO}$ nanorods synthesized by plasma-enhanced chemical vapor deposition. J. Appl. Phys., 95(6), 3141-3147. https://doi.org/10.1063/1.1646440

10. Fardood, S. T. et al. (2019). Green synthesis of $\mathrm{ZnO}$ nanoparticles via sol-gel method and investigation of its application in solvent-free synthesis of 12-Aryltetrahydrobenzo[ $\alpha]$ xanthene-11-one derivatives under microwave irradiation. Chem. Method., 3, 632-642. https://doi.org/10.33945/SAMI/CHEMM.2019.6.2

11. Li, S.-M. et al. (2017). Acetone sensing of $\mathrm{ZnO}$ nanosheets synthesized using room-temperature precipitation. Sens. Actuators B: Chemical, 249, 611-623. http://doi.org/10.1016/j.snb.2017.04.007

12. Vinayagam, R., Varadavenkatesan, T. \& Selvaraj, R. (2017.) Green synthesis, structural characterization and catalytic activity of silver nanoparticles stabilized with Bridelia retusa leaf extract. Green Process Synth., 7(1), 1-8. https://doi.org/ 10.1515/gps-2016-0236

13. Sirdeshpande, K. D. et al. (2018). Structural characterization of mesoporous magnetite nanoparticles synthesized using the leaf extract of Calliandra haematocephala and their photocatalytic degradation of malachite green dye. Appl. Nanosci., 8(4), 675-683. https://doi.org/10.1007/s13204-018-0698-8

14. Fardood, S. T. et al. (2020). Green synthesis, characterization, and photocatalytic activity of cobalt chromite spinel nanoparticles. Mater. Res. Express., 7, 015086. https://doi.org/10.1088/2053.1591/ab6c8d

15. Gawade, V. V. et al. (2017). Green synthesis of $\mathrm{ZnO}$ nanoparticles by using Calotropis procera leaves for the photo-degradation of methyl orange. J. Mater. Sci. Mater. Electron, 28, 14033-14039.

16. Fardood, S. T. et al. (2019). Biosynthesis of $\mathrm{MgFe}_{2} \mathrm{O}_{4}$ magnetic nanoparticles and their application in photodegradation of malachite green dye and kinetic study. Nanochem. Res., 4(1), 86-93. https://doi.org/10.22036/ncr.2019.01.010

17. Fardood, S. T. et al. (2019). Eco-friendly synthesis and characterization of $\alpha-\mathrm{Fe}_{2} \mathrm{O}_{3}$ nanoparticles and study of their photocatalytic activity for degradation of Congo red dye. Nanochem. Res., 4(2), 140-147. https://doi.org/10.22036/ncr .2019 .02 .005 
18. Atrak, K., Ramazani, A. \& Fardood, S. T. (2019). Green synthesis of $\mathrm{Zn}_{0.5} \mathrm{Ni}_{0.5} \mathrm{AlFeO}_{4}$ magnetic nanoparticles and investigation of their photocatalytic activity for degradation of reactive blue 21 dye. Environ. Technol., 41(21), 1581841. https://doi.org/10.1080/09593330.2019.1581841

19. Azar, B. E., Fardood S. T. \& Morsali, A. (2019). Green synthesis and characterization of $\mathrm{ZnAl}_{2} \mathrm{O}_{4} @ \mathrm{ZnO}$ nanocomposite and its environmental applications in rapid dye degradation. Optik, 208, 164129. https://doi.org/10.1016/ j.ijleo.2019.164129

20. Vanathi, P. et al. (2014). Biosynthesis and characterization of phyto mediated zinc oxide nanoparticles: A green chemistry approach. Mater. Lett, 134, 13-15. https://doi.org/10.1016/j.matlet.2014.07.029

21. Sangeetha, G., Rajeshwari, S. \& Venckatesh, R. (2011). Green synthesis of zinc oxide nanoparticles by aloe barbadensis miller leaf extract: Structure and optical properties. Mater. Res. Bull., 46, 2560-2566. https://doi.org/10.1016/j. materresbull.2011.07.046

22. Fardood, S. T., Ramazani, A. \& Joo, S. W. (2017). Sol-gel synthesis and characterization of zinc oxide nanoparticles using Black Tea extract. J. Appl. Chem. Res., 11(4), 8-17. http://jacr.kiau.ac.ir/article_536676.html

23. Samat, N. A. \& Nor, R. M. (2013). Sol-gel synthesis of zinc oxide nanoparticles using Citrus aurantifolia extracts. Ceram. Int., 39, S545-S548. https://doi.org/ 10.1016/j.ceramint.2012.10.132.

24. Pai, S. et al. (2019). Photocatalytic zinc oxide nanoparticles synthesis using Peltophorum pterocarpum leaf extract and their characterization. Optik, 185, 248255. https://doi.org/10.1016/j.ijleo.2019.03.101

25. Ramimoghadam, D., Hussein, M. Z. B. \& Taufiq-Yap, Y. H. (2012). The effect of sodium dodecyl sulfate (SDS) and cetyltrimethylammonium bromide (CTAB) on the properties of $\mathrm{ZnO}$ synthesized by hydrothermal method. Inter. J. Mol. Sci., 13, 13275-13293. https://doi.org/10.3390/ijms131013275

26. Varadavenkatesan, T. et al. (2019). Photocatalytic degradation of Rhodamine B by zinc oxide nanoparticles synthesized using the leaf extract of Cyanometra ramiflora. J. Photochem. \& Phtobio. B: Biol., 199, 111621. https://doi.org.10.106/ j.jphotobiol.2019.111621

27. Yedurkar, S., Maura, C. \& Mahanwar, P. (2016). Biosynthesis of zinc oxide nanoparticles using Ixora Coccinea leaf extract-a green approach. Open J. Synth. Theo. Appl., 5(1), 1-14. https://doi.org/10.4236/ojsta.2016.51001

28. Paraguay, F. et al. (2000). Influence of $\mathrm{Al}, \mathrm{In}, \mathrm{Cu}, \mathrm{Fe}$ and $\mathrm{Sn}$ dopants on the response of thin film $\mathrm{ZnO}$ gas sensor to ethanol vapor. Thin Solid Films, 373, 137-140. https://doi.org/10.1016/S0040-6090(00)01120-2

29. Wei, A., Pan, V. \& Huang, W. (2011). Recent progress in the ZnO nanostructurebased sensors. Mater. Sci. Eng. B, 176(18), 1409-1421. https://doi.org/10.1016/ j.mseb.2011.09.005 